\title{
Repatriation of self-initiated expatriates: expectations vs. experiences
}

\author{
David R. Ellis and Kaye Thorn \\ School of Management, Massey University, Auckland, New Zealand, and \\ Christian Yao \\ School of Management, Victoria University of Wellington, Wellington, New Zealand
}

\begin{abstract}
Purpose - While there is a burgeoning literature on self-initiated expatriates (SIEs), the emphasis has been on expatriation not repatriation. The purpose of this paper therefore is to explore how repatriating SIEs perceive the experience of repatriation compared with their pre-repatriation expectations. Further, we examine the seminal work of Black et al. (1992) in the light of current day realities.

Design/methodology/approach - This qualitative research draws on interviews with SIE New Zealanders returning home. It is an exploratory longitudinal study, based on interview data collected prior to $(n=32)$, and after $(n=27)$ repatriation, comparing expectations and experiences of repatriation.

Findings - Findings show that there is a strong level of congruence between the expectations of the return and their experience of repatriation. This congruence eases the transition and mitigates the impact of reverse culture shock. We revise Black et al.'s framework of repatriation adjustment to more accurately reflect the expectations and experiences of repatriating SIEs, recognising the importance of individual agency and the impact of today's technological advances on repatriation.

Research limitations/implications - The contributions of this paper include clarification of repatriating SIEs. Further, through the revision of the framework, we identify new areas of research that would aid our understanding of repatriating SIEs and lead to the development of a more detailed model. We highlight the interplay between variables showing how these might mitigate the shock of repatriation.

Originality/value - Repatriation is an under-researched phase of the SIE, and this study provides empirical data that contributes to our understanding of the construct. Black et al.'s framework of repatriation adjustment is revised in the context of contemporary SIE, highlighting the holistic nature of self-initiated expatriation and repatriation, viewing the events not as discrete, but as a continuum of time.
\end{abstract}

Keywords Repatriation, Longitudinal study, Self-initiated expatriation, Re-adjustment

Paper type Research paper

\section{Introduction}

The diverse nature of the international mobility landscape has resulted in a proliferation of studies of the global workforce. One form of mobility that has attracted considerable interest in recent times is self-initiated expatriation (SIE), where people go abroad to seek opportunities on their own initiative instead of being assigned to a host country (Doherty et al., 2013). It has been over 20 years since SIEs were identified as a separate population of the globally mobile (see, e.g. Inkson et al., 1997; Suutari and Brewster, 2000), but there are no statistics which definitively identify the size of the SIE population. There is, however, a clear understanding that SIEs make up a significant portion of the expatriate population (Hasleberger and Vaiman, 2013). For this reason, a large number of studies of SIEs has occurred as a comparison with assigned expatriates (AEs) (e.g. Andresen et al., 2014; Dickmann et al., 2018; McNulty and Brewster, 2017; Suutari et al., 2018). There are also empirical studies focusing specifically on SIEs, with topics ranging from motivation (Thorn, 2009), adjustment (Froese, 2012), embeddedness (Meuer et al., 2019), career development issues (Brewster et al., 2019; Selmer and Lauring, 2012) and SIE in developing countries (Jannesari and Sullivan, 2019). A limitation in our current understanding of SIEs, however, is that most of the knowledge is related to the process of expatriation (i.e.

Received 15 September 2019 Revised 23 February 2020 Accepted 18 May 2020 
going from the home country to a host country) and the issue of repatriation (i.e. the return of the SIE to the home country) has not received commensurate attention (Chiang et al., 2017; Lazarova, 2014). There have been repeated calls for more research into repatriating SIEs (A1 Ariss and Crowley-Henry, 2012; Chiang et al., 2017; Doherty et al., 2013).

The challenges of repatriation of AEs have long been discussed in the literature, and the tone of research findings in this area is summarised by Altman and Baruch (2012, p. 244) as "notoriously a troublesome time for expatriates". Adjustment to the home country and career issues top the list of these challenges (Andresen and Walther, 2013; Guo et al., 2013; Kraimer et al., 2016). The theoretical basis for much of the research on repatriation is the discrepancy between what the expatriate expects the return home to be like, and the reality of the actual situation (Szkudlarek, 2010). The notion that readjustment difficulties are unexpected is key here, and it is both this unexpectedness and the extent of the unmet expectations that results in "reverse culture shock" (Martin, 1984) and poor adjustment in the home country. However, it is not yet clear how, or even whether, this similarly applies to the repatriation of SIEs, especially given the identified differences between AEs and SIEs.

Adjustment challenges are acknowledged in the limited SIE repatriation literature. For example, using a comparative approach, Begley et al. (2008) suggest that work readjustment might be more difficult for repatriating SIEs than for AEs. Similarly, Andresen and Walther (2013) find significant differences in the reception of returning SIEs in the French, German and Danish employment markets. Tharenou and Caulfield (2010) argue that host country pull (weak embeddedness), home country pull and shocks explained SIRs' intention to repatriate and that shocks also play a key role in explaining job search and repatriation. Cultural differences highlight the contextual influence on finding a suitable job for those returning to their home country (Guo et al., 2013). These studies share a common limitation in that they mainly focus on work adjustment and we have limited empirical understanding of other aspects of repatriation adjustment. Repatriating SIEs, like AEs, experience varying types of readjustment challenges upon their return including work and non-work considerations (Baruch et al., 2016).

Another limitation in the existing repatriating SIE literature is that studies tend to focus on either the intention to repatriate (e.g. Lindsay et al., 2019; Tharenou and Caulfield, 2010) or the outcomes after repatriations (e.g. Begley et al., 2008; Cao et al., 2014). There is lack of a holistic understanding of repatriation as a process. Taking temporal factors into the investigation, we contribute to this gap by considering how the expectation of the repatriation compares with the actual experience. More specifically, we explore the process of re-entry for SIE New Zealanders, comparing our findings with the Black et al. (1992)'s theoretical framework of repatriation and providing new interpretations of adjustment proactivity that may be more relevant to returning SIEs. This exploration contributes much-needed contemporary mobility theory which specifically addresses SIEs' re-adjustment, challenging seminal repatriation adjustment theory and answering Tung's (2016) call to "fundamentally rethink the parameters. .... [so that our research] more accurately reflects the realities of the world we live in" (p. 149). We also provide empirical evidence of repatriating SIEs, addressing recent calls for a more systematic exploration of this under-researched group (Chiang et al., 2017; Lazarova, 2014). First, however, we define our construct.

\section{Conceptual clarification}

The need for clarification of terminology is particularly noted in the SIE literature (Andresen et al., 2014; Doherty et al., 2013) where the conceptual constructs are either not fully explicated, ill-defined, overlapping or poorly operationalised (McNulty and Brewster, 2017). Defining repatriating SIEs is important in an examination of their adjustment for two reasons. First, and as noted above, there is limited research undertaken on this group. Second, the literature points to significant differences between AEs' and SIEs' expatriation and it is anticipated that 
there will be differences also in repatriation, based on diverse motives, support offered and the work situation on return to the home country.

Self-initiated repatriation (SIR) is a term that is found in the literature, but similar confusion is noted. For example, a qualitative study of 20 Chinese SIRs includes former AEs and international students in the research sample (Guo et al., 2013) while Andresen and Walther (2013) fail to specify the selection criteria of their sample. Although the participants returned to their home countries of their own volition, many had left as AEs. Because of this confusion, and because SIE is a recognised concept in the literature, in this paper, we have retained the SIE term and refer to repatriating SIEs.

To ensure the conceptual clarification of repatriating SIEs for the purpose of examining their adjustment, we have endeavoured to be both very specific and narrow in defining our population. We consider that repatriation is an extension of SIE in that it is the return home, and that in order to be a repatriating SIE, you must first be a SIE. Although presented in different ways, both Doherty et al. (2013) and Cerdin and Selmer (2014) identify four key criteria defining SIE. These are (1) that the relocation across countries must be self-initiated, (2) employment must be regular and secure (as opposed to casual employment which is often associated with people on their overseas experience (OE) (Doherty et al., 2013), (3) there must be the intention of a temporary stay and (4) the expatriate must be skilled or have professional qualifications. We adopt these criteria in our characterisation of an SIE.

Further, in this article, we define repatriating SIEs according to three additional conditions - first, the individual initiated their own expatriation (i.e. was a SIE, having met the four criteria above); second, the return move is initiated by the individual; and third, the individual also returns unaided by an employer (i.e. is self-funded) (Begley et al., 2008; Tharenou and Caulfield, 2010). While recognising that there may be some overlap and that other returnees may have some of these characteristics also, the definition of repatriating SIE that we adopt must include all of these aspects. For example, while an AE may choose to return home prior to the completion of the formal assignment, and thus appear to meet the second criteria, the original expatriation was not self-initiated (condition 1) and the return would probably be company assisted (condition 3). Similarly, while a person on their OE may meet conditions two and three, their employment is casual and not career enhancing (Cerdin and Selmer, 2014), and thus they do not meet the definition of an SIE. These three conditions therefore ensure the delineation of repatriating SIEs from other mobile individuals and reduce the confusion presented by the term SIR in previous studies.

While we have provided a clear definition of a repatriating SIE, it remains empirically unclear how to differentiate the repatriation of SIEs from that of returning AEs. There is very limited research on the repatriation of SIEs, so most of our knowledge must be drawn from research on the repatriation of AEs. Table 1, therefore, presents findings from recent metaanalyses and other studies which examine the repatriation literature over the last three or four decades, and we summarise the main differences between returning SIEs and AEs, postulating on how these differences might impact the readjustment process. The table highlights contradictions in the published findings - for example there is disagreement about the impact of age on adjustment, and there are mixed results about the implications of the duration of time abroad.

AEs and SIEs share similarities in terms of the returning motives, processes and challenges. Yet, a closer examination sheds light on the uniqueness of SIEs which contribute to adjustment issues. This group of people are less homogenous, have no organisational support during their return and face different career uncertainties and challenges after return. One of the key differences between AEs and SIEs highlighted in the table is the initiation of the expatriation and the repatriation. Although it is probable that most AEs agree to or even make themselves available for expatriation (Harris and Brewster, 1999), the SIE shows considerable individual agency in independently deciding to leave the home country,
Repatriation of SIEs 


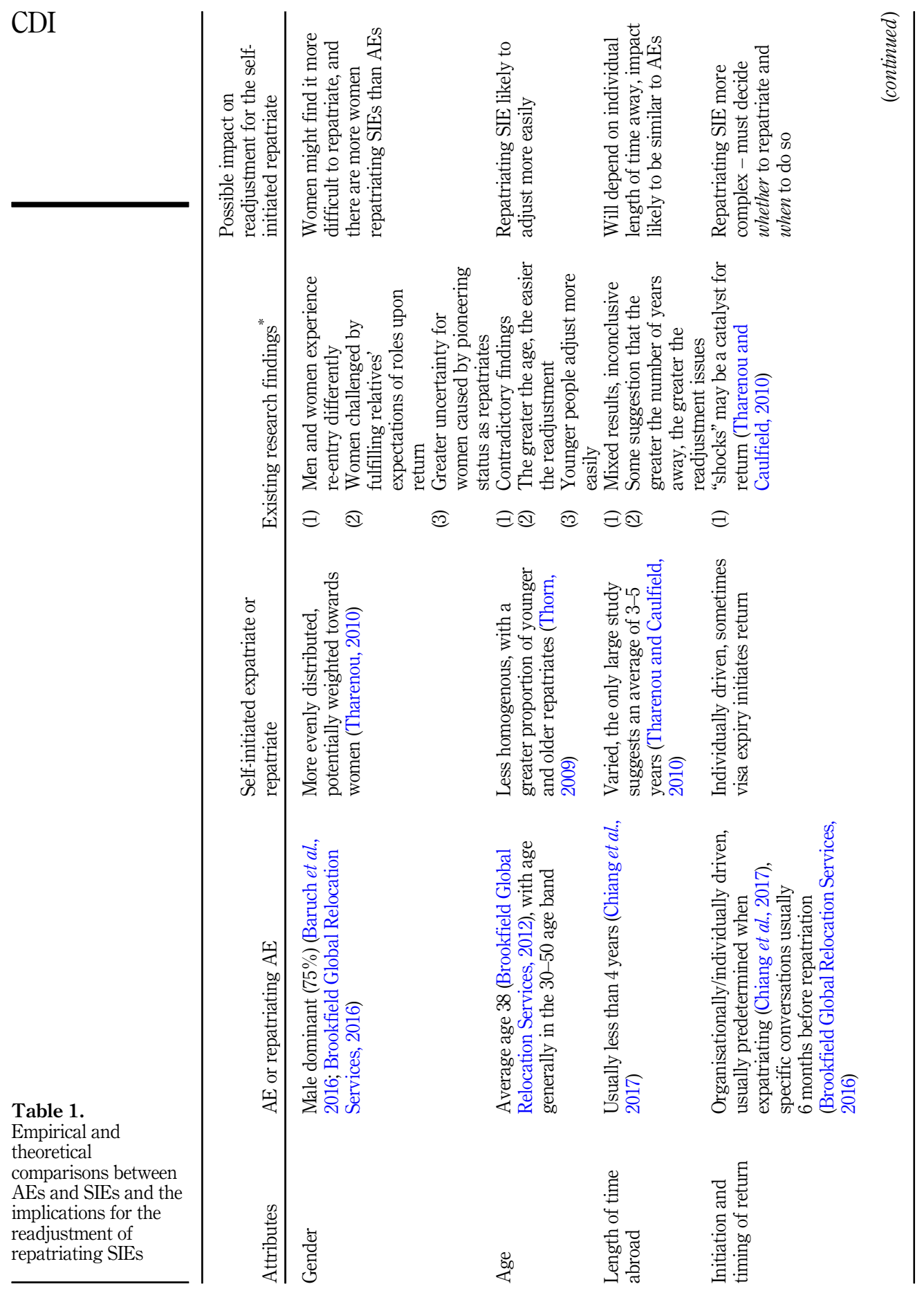




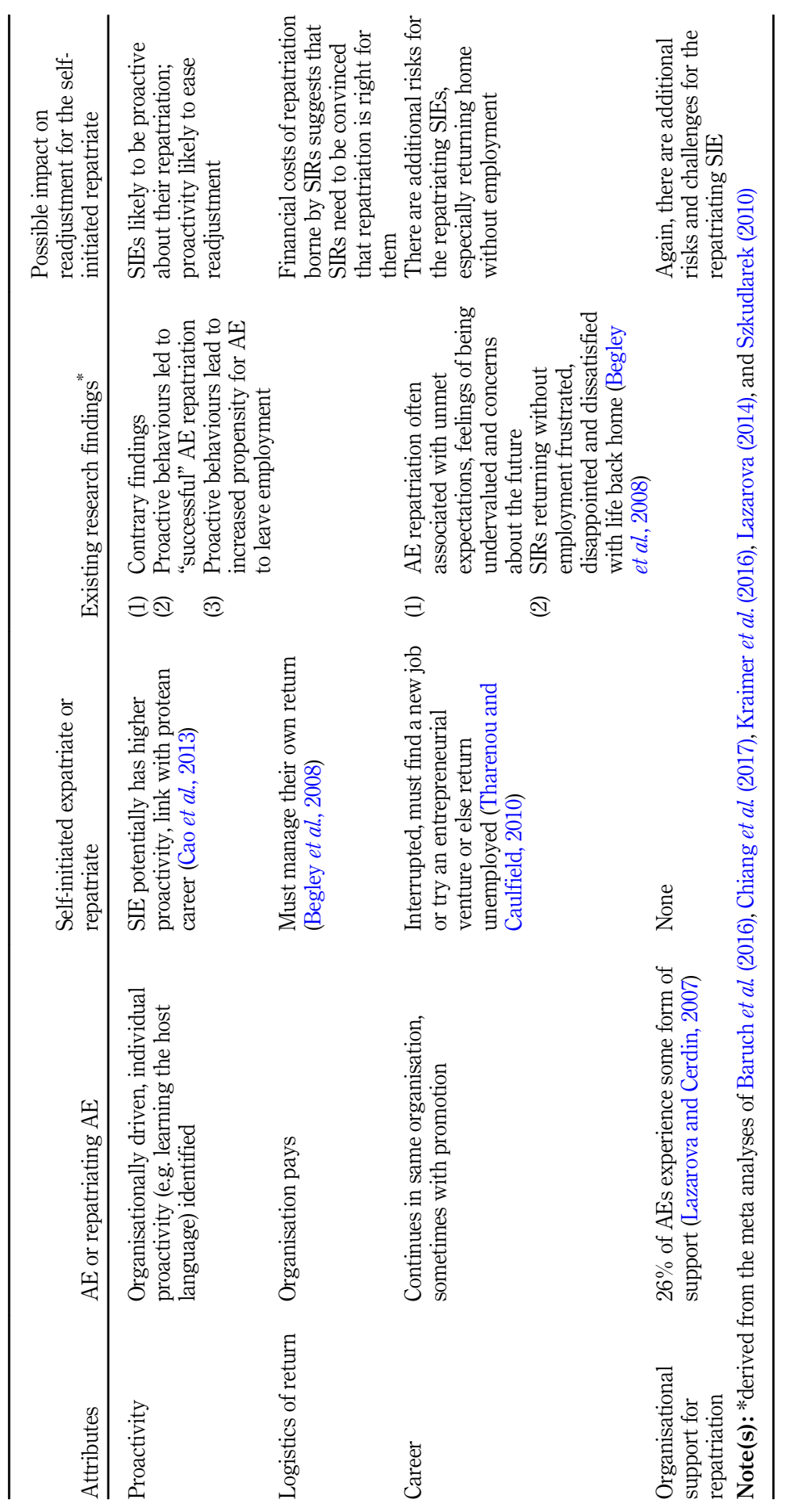

Repatriation of SIEs

Table 1. 
then again when they decide if and when to come home. Thus, the SIE may display more proactive behaviour than AEs. The implications of this and other differences on readjustment are unknown.

\section{Theoretical background: repatriation adjustment}

We build our theoretical understanding of repatriation adjustment from research of returning AEs, and in some cases, research grouping AEs and SIEs together (see, e.g. Guo et al., 2013). Different theoretical lenses have been used in examining repatriation adjustment including, for example, reacculturation theory (Martin, 1984), expectations theories (Goss and Hynes, 2005), cultural identity theories (Sussman, 2002) and re-entry adjustment theories (Martin and Harrell, 2004). While these theories explore the experiences of readjusting to a home country from different perspectives, they all conclude that readjustment difficulties emerge from the mismatch between the repatriate's expectations and actual experiences (Kraimer et al., 2016). Early research suggests that the re-entry process can be even more difficult than the move to the foreign country primarily because of a lack of recognition of their international experiences by organisations and friends (Adler, 1981), although more recent evidence argues that technological advances and constant communication flows bridge the gap between expectations and reality (Cho et al., 2013) This suggests that readjustment is not as challenging today as it used to be.

The AE literature, not unexpectedly, focuses on the organisation and the role of the AE with respect to that organisation. Hence it highlights the misalignment between the organisation and the individual's expectations, and the impact of changes to organisation structure or role content that occurred in the expatriate's absence (Forster, 1994; Stroh et al., 1998). The issue of retention or rather, the high rate of repatriate's resignation, is another strong theme (Cerdin and le Pargneux, 2009; Lazarova and Cerdin, 2007), with scholars emphasising the need for communication, post-expatriation training and career interventions to retain talent (Baruch et al., 2016). There is limited research detailing how repatriates' experiences match their expectations and the impact of this on readjustment. In other words, there is a need to understand the factors that influence repatriation in contemporary society, the role of individual agency and contextual factors that could assist readjustment. Individual willingness such as attitudes towards re-entry could predict job and non-job satisfaction after return (Shaffer and Harrison, 1998). The issue of proactivity has been discussed in the literature, with suggestions that AEs who display proactive career behaviours are either more likely to stay with the organisation (a "successful" repatriation) (O'Sullivan, 2002) or in a contrary interpretation are more likely to move onto new and better employment (Lazarova and Cerdin, 2007). Again, however, we note that this research is derived from AEs, where the role of the organisation is paramount, and we do not know the implications of proactivity on readjustment for SIEs.

Research on expectations of repatriating SIEs is sparse and most of our current understanding is related to the intention to repatriate (Lindsay et al., 2017), reception in the home country (Begley et al., 2008) or career outcomes (Guo et al., 2013). Black et al.'s (1992) cultural adjustment framework is therefore an important theoretical model and one of the few that is specific to repatriation adjustment. It attempts to bring the factors impacting readjustment of AEs into a coherent model and is the most applied theory, used by over $20 \%$ of the repatriation literature (Szkudlarek, 2010; Knocke and Schuster, 2017). Fundamental to this framework is the suggestion that a repatriate knows that they would be returning, and they are able to make anticipatory adjustments prior to returning home. Further adjustments occur after arriving in the home country ("in-country adjustments"). Hence their model incorporates two temporal dimensions, before the return and after the return. Black et al. (1992) separate repatriation expectations and adjustment into three categories - work, interaction (exchanges with host nationals) and general (e.g. housing, cost of living, quality of 


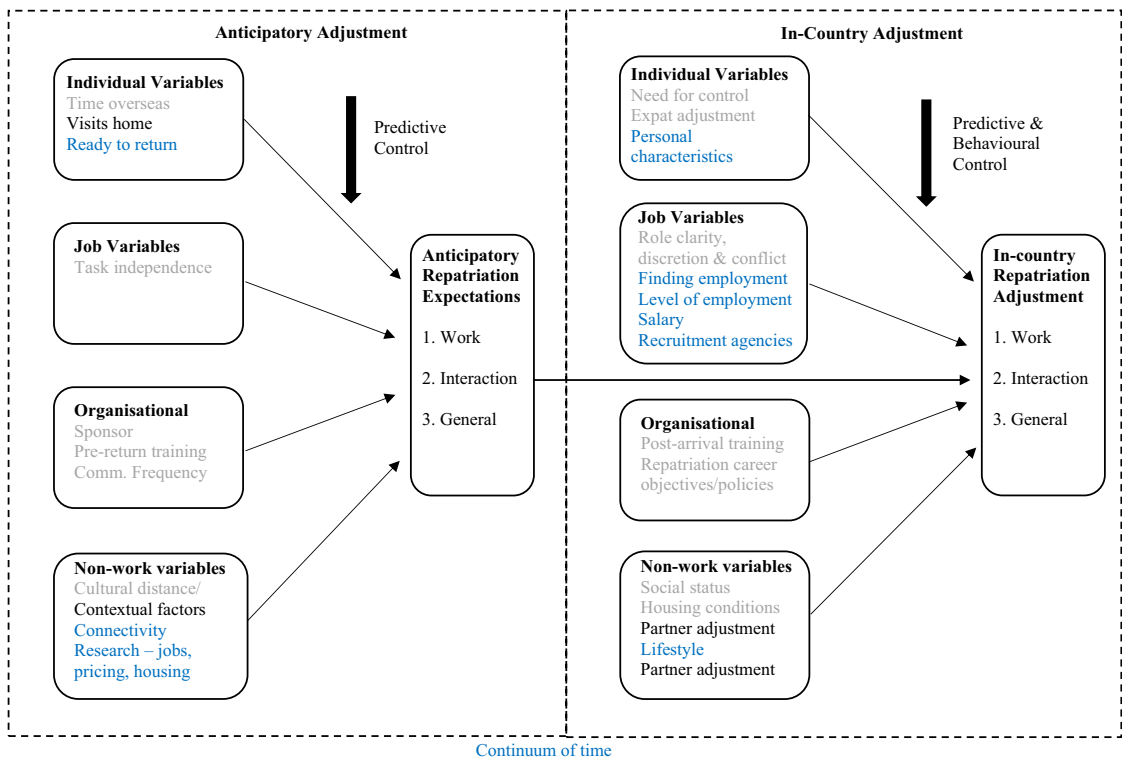

Repatriation of SIEs

Figure 1.

Factors affecting the readjustment of repatriating SIEs

life). The model also highlights the individual, job, organisational and non-work variables that affect both anticipatory adjustments and in-country adjustments, introducing a situational component to adjustment and recognising that individuals encounter different types of difficulties at different times and in different places (Fitzpatrick, 2017).

Although Black et al.'s (1992) model remains the predominant approach in the repatriation literature, most academic studies have only focused on partial analysis of the model with only limited quantitative testing (e.g. Vidal et al., 2010). We acknowledge that the research behind this framework (Black and Gregersen, 1991) has been criticised. In particular, Lazarova et al. (2010) suggest that Black and Gregersen's model does not incorporate adjustment to changing family roles, with specific reference to the changed roles of both the expatriate in the new work environment and the trailing spouse. They propose a tripartite conceptualisation of expatriate adjustment incorporating cultural, work role and family roles. While this criticism is pertinent for their consideration of expatriate work and family performance, and adjustment to the expatriation, it is not as appropriate as Black et al.'s framework for the consideration of the experience of repatriation.

Given the limitations of our current understanding of the repatriation of self-initiated expatriates as a holistic process and the limited body of (qualitative) evidence on the applications of Black et al.'s (1992) model, the primary research question addressed in this article is how do repatriating SIEs perceive the experience of repatriation compared with their pre-repatriation expectations? Following on from this, the secondary question is how does this experience of return inform our understanding of Black et al.'s seminal framework, in the context of contemporary repatriating SIE readjustment?

\section{Method}

The aim of this study was to build theory in the sparsely researched field of repatriation of SIEs and to extend existing theory by making it "more dense by filling in what has been left out" (Pratt et al., 2006, p. 103). We adopted a qualitative, inductive approach to building knowledge through interpretivism, given the near absence of research on SIE repatriation. 
Our focus was on New Zealand SIEs so we combined both purposeful and snowball sampling through online organisations (e.g. Kiwi Expatriates Abroad Network) and personal networks. New Zealand provides a useful context to research SIE issues. The flow of New Zealanders to other countries has long been a concern to government. OECD research shows that $14.1 \%$ of New Zealanders are living abroad, second only to Ireland (OECD, 2014). The small size of the economy, offering limited opportunities for career development, is one of the key drivers for mobility (Inkson et al., 2013). Some years ago, Doherty et al. (2011) proposed that $65 \%$ of expatriates in the Western world are self-initiated. Recent trends suggest SIEs represent an increasing component of global mobility (Andresen et al., 2014), and, given the limited opportunities for assigned expatriation in New Zealand (few multinational corporations), the percentage of SIEs from New Zealand is likely to be higher. While many New Zealanders currently live abroad, research from industry (see, e.g. KEA New Zealand, 2015) and academia (Lindsay et al., 2017) both indicate an intention for New Zealanders to return home. Understanding the expectations and experiences of repatriating SIEs is therefore critical, and a prerequisite to building knowledge to effectively manage them.

The selection of participants was guided by the definition of repatriating SIEs provided. They must also have spent at least one year living and working abroad (Begley et al., 2008) to ensure that the participants had actually settled in the host country, and eliminating shortterm tourists or business travellers who, as identified by McNulty and Brewster (2017), are not SIEs. As most of the SIE literature focuses on highly skilled or professional workers (Doherty et al., 2013), we selected participants who had university qualifications or extensive professional experience.

Based on the consensus that readjustment is difficult if expectations do not match the experience of repatriation, two phases of interviews were conducted, capturing before repatriation expectations and after repatriation experiences of the participants. Thus, while the interviews were at two specific points, the narrative of the participants covered the whole repatriation experience, from initiating and planning to repatriate, with the associated anticipatory readjustment expectations, through to post-repatriation reflections. For phase two, 27 participants remained (84\% of phase one's 32 participants), with the others having made the decision not to return at this stage. Table 2 provides a summary of the sample's characteristics and interview details.

An initial interview guide was developed covering general topic areas derived from the literature, but the ability to move the discussion with the participant was a key driver (Mason, 2002). In the first phase, the data collected related to participants' expectations for repatriation - in the parlance of Black et al. (1992), the anticipated aspects of their readjustment, incorporating both work and non-work variables. Non-work topics were discussed because work and personal life satisfaction crossover has been found in research on repatriating SIEs (Begley et al., 2008). In the second phase, the objective was to collect data relating to the actual repatriation experiences - the in-country readjustment. Participants were encouraged to use specific examples and stories during both phases to supply the narrative later scrutinised. The data from both phases were analysed thematically using NVivo 10. Following Thomas (2006), we achieved data reduction by first, breaking the narrative fragments - or sections of stories - within the transcripts into "thought units" reflecting distinct thoughts, which correspond loosely to sentences. Second, the thought units were read several times and then labelled with codes (Cappellen and Janssens, 2010). Coding was inductive, reflecting the limited literature on repatriating SIEs, and themes were identified from within the data. Third, the codes were sorted into categories $(n=47)$ and subcategories $(n=144)$, then grouped into themes. At the highest level, these themes are separated into congruences and incongruences, and then, at the next level, and similar to Black et al. (1992), divided into work and non-work variables. The "constant comparative method" (Lofland et al., 2006) was used here to compare how different themes were discussed 


\section{Participants}

Number of participants

Average age (range)

Average time in current host country (range)

First period living as expatriate

Yes

No

Phase one
32
36 (26-65)
7.5 years (1-29 years)

17

15

Host country location

England

Belgium

Australia

Canada

Hong Kong

Ireland

Japan

USA

Highest qualification

$\mathrm{PhD}$

Master's degree

Bachelor's degree

Diploma

\section{Repatriation} of SIEs

27

Timing of phase 2 interview (after repatriation)

3-4 months

5-6 months

7-8 months

Employment status

Working

Looking for work

Not looking for work

$\begin{array}{ll}32 & 24 \\ 0 & 2 \\ 0 & 1\end{array}$

Industry of employment

Accounting

5

Banking

Education and research

Engineering

General management

IT

HR and recruitment

Legal

Marketing

Project management

Sales

Administration

Not reported

2

3

1

2

1

4

1

3

5

2

0

3

Note(s): ${ }^{1}$ One accountant is not currently looking for work, one has yet to find employment and the other did not repatriate; ${ }^{2}$ One participant has taken part-time administrative work as she now has a baby; ${ }^{3}$ Still looking for work; ${ }^{4}$ One participant changed roles from project management to general management in the health industry; ${ }^{5} \mathrm{Did}$ not repatriate

Table 2.

A summary of the participants

by different participants. This process served as an internal validation tool to enhance the credibility and robustness of the research. 


\section{Results}

In this section, our focus is to first present findings comparing the experiences of repatriation to pre-repatriation expectations. Then, delving deeper, we explore the factors that lie beneath the similarities and differences, affecting the process of re-adjustment. Table 3 summarises the findings by theme and provides quotes which exemplify each theme.

\section{Expectations vs. experience}

Overall, the narratives reveal a relatively high level of congruence between participants' expectations and their experiences, and where differences occurred, most represented positive surprises, in that the reality of life back home was better than expected. One participant's comments during the phase two interviews highlight this:

Do you know, it was so easy to settle in, and it was shockingly easy to settle in. It's helped by the fact that we've had such a cracking summer, and who can argue with the fact you can go to the beach every day and that sort of thing, which has just been amazing. (Anna)

Despite being able to identify differences between the New Zealand work culture and that of their host country and the expected challenges that they experienced from their interactions with recruitment agencies, all participants reported an easy re-adjustment to work in New Zealand. This could be due to the fact that all of the participants were well-educated and many had more than five years working experience in their field. Another reason could be that most of the participants worked in host countries where the cultural differences are relatively small compared to New Zealand.

This easy adjustment also extended to participants' personal and social lives. New Zealand's lifestyle was an important factor in participants' assessment of the repatriation experience, and indeed of their decisions to repatriate. All participants anticipated a better lifestyle. None of the participants said they regretted repatriating, and in many cases, they were ready to leave. However, most said there were things they missed about their host countries - the excitement of the big cities, and friends made while abroad.

This loss of social contacts was compensated by the new social connections made at home and participants felt that social reintegration experiences were generally easy as expected, with few concerns expressed. Where participants had difficulty reconnecting with former social contacts, this tended to be due to perceptions of having less in common, usually due to either the friends not having lived abroad or one party having had children.

In the work realm, differences between the expectations of life back home in New Zealand and the reality were noted. They were, however, predominantly positive, in that the experience of finding work, the recognition of their skills and the associated remuneration were better than anticipated. The initial response to finding work pre-repatriation was overwhelmingly pessimistic, with the vast majority feeling that work and career opportunities available in New Zealand were inferior to those found in the host countries. Exacerbating this fear was a perception that their lack of current New Zealand experience would mean that they would have to re-enter the job market at a lower level. At the phase 2 interviews, however, only two participants were still looking for work, so their job search had been largely successful. Similarly, their expectations about lack of current experience were not fulfilled. Over half of the participants anticipated a reduction in remuneration on their return, with a further third expecting a similar pay package. The reality, however, was more positive, and of the 21 participants who commented on remuneration at the phase 2 interviews, 12 received what they expected, eight more than they thought, and just one received less money.

Work-life balance was also a positive surprise for many and, given the salience of this as a driver for repatriation, it was important that it at least lived up to expectations. In the phase 2 


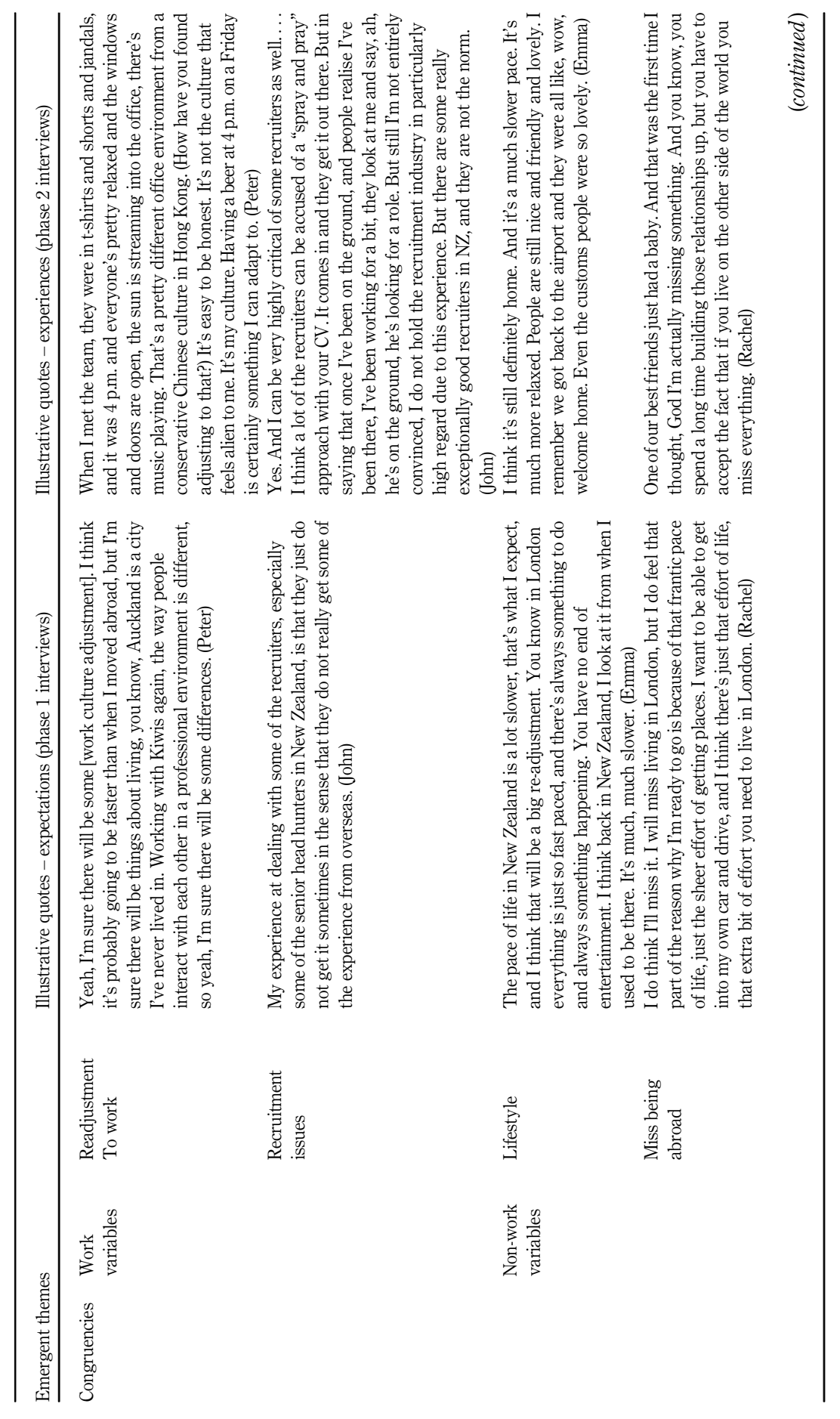

Repatriation of SIEs

Table 3.

Categorisation of themes - expectations versus experiences 
CDI

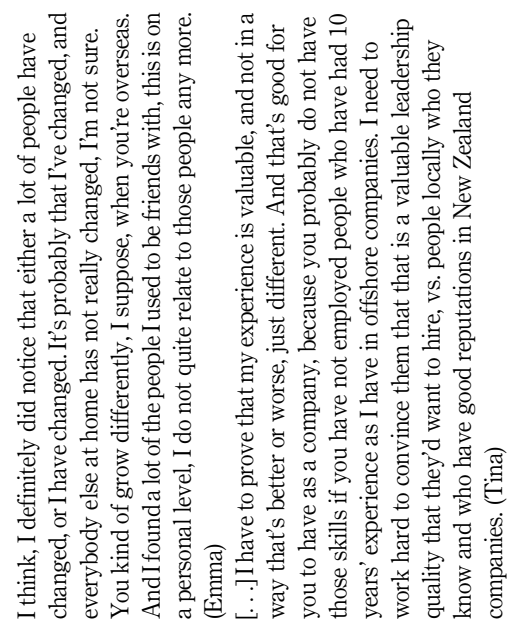

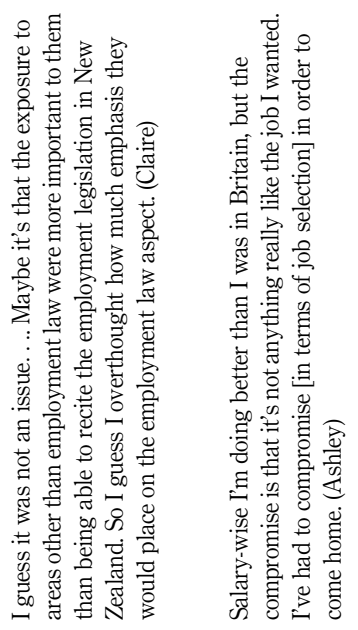

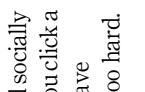

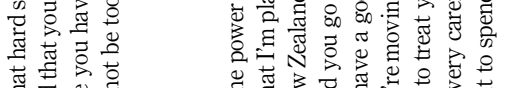

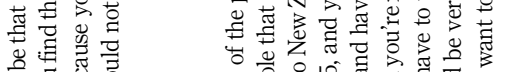

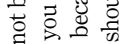

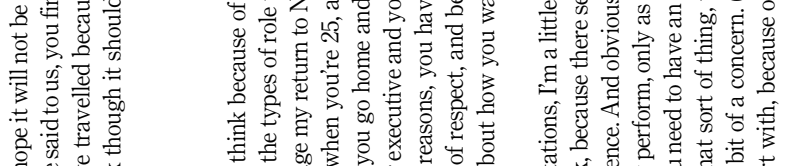

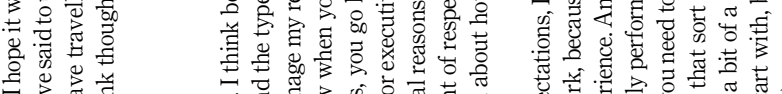

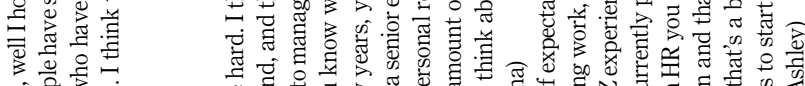

o

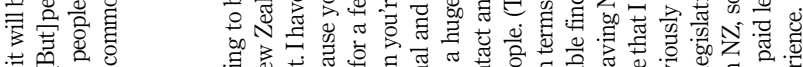

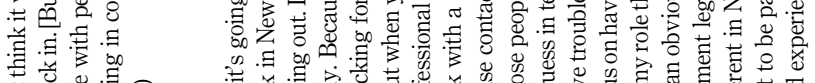

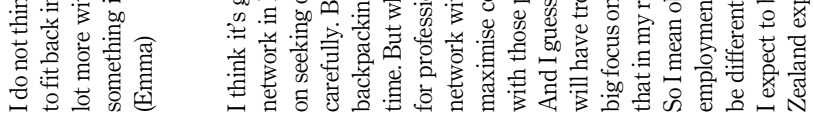

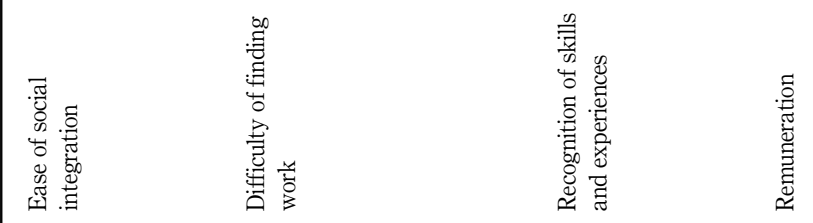

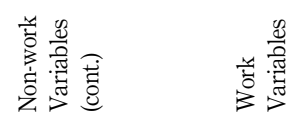

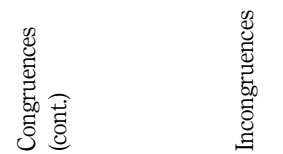




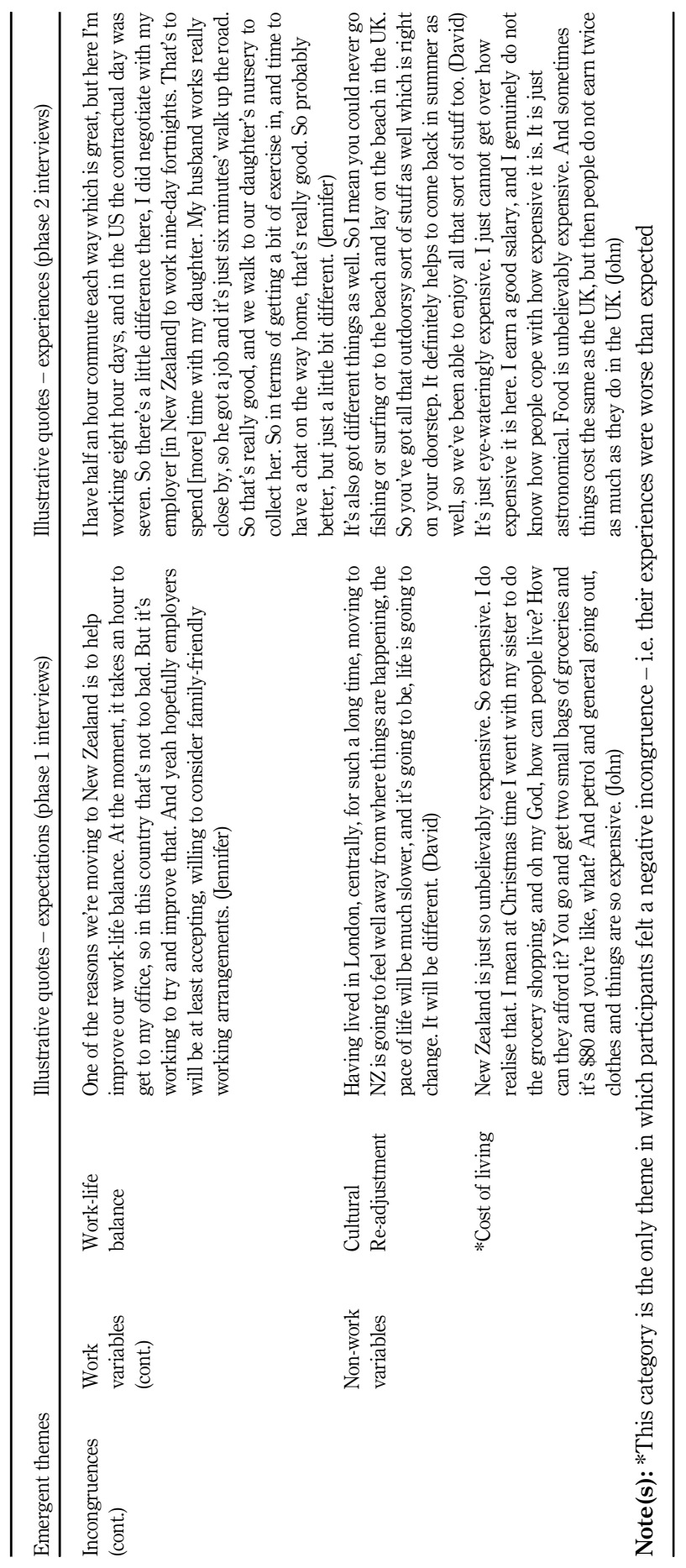

Repatriation of SIEs

Table 3. 
interviews, 17 participants returned to this theme, 12 of whom considered their work-life balance to be better than anticipated. The key advantage expressed was more time to spend with family. Participants also found it easier than anticipated to fit back in to the cultural environment they had left.

There were two key themes in the non-work arena where a misalignment was noticed. In the phase 1 interviews, a majority of participants $(n=28)$ perceived a high cost of living in New Zealand, and this theme was discussed with more passion than any other topic:

If you compare dollar for pound, it seems attractive, but I know that wages are less than over here, so to me the cost of living in comparison to salary, it's more expensive to live in New Zealand than it is to live in the UK. So that's something we'll also take into account. I mean, we'll quite happily go out for dinner once or twice a week in the UK. We could never afford to do that in New Zealand. (Jennifer)

Even with this expectation, participants later expressed an underestimated magnitude of the cost of living once arrive in New Zealand, especially when considered in relation to its impact on disposable income:

The cost of living was a real shock. Just the cost of petrol and groceries and everything else. It's London prices, but the rent and the houses are just extremely expensive. We really wonder how people survive here and maintain a quality of life. (Jennifer, phase 2)

In summary, participants' accounts of their work and non-work experiences revealed a mixture of congruences and incongruences although the incongruences were largely positive, and the concept of reverse culture shock, on the surface, seems inapplicable. To seek explanations for this outcome and in order to answer the second research question, we delved further into the data to identify the reasons for the level of congruence identified.

\section{Explaining the congruences and incongruences}

Most participants provided thoughts on the relative ease of their repatriation. They talked of having a "flexible" personality that suits both host and home country environments, being at a career stage that matched current job market demands, being well-organised from a logistical perspective and feeling ready to move - "it was just time to go" (Maria, Phase 1). The role of the partner was also identified as an important variable as, when asked about readjustment, many participants related their answers to their partners. This tended to happen regardless of whether the partner was also a repatriate New Zealander. Concerns in relation to partners tended to centre around difficulties finding or adjusting to work. In Hayley's case, for example, the difficulties experienced by her English partner impacted their assessment of the decision to move to New Zealand:

He's actually finding it very hard. Much harder than he ever thought, which is hard on me. He's finding it quite a shock, you know, not all bad, but commercially quite a shock. He's quite shocked at how difficult it is to engage with people and make connections. He has found the recruitment very, very difficult, very unprofessional and unhelpful. And he's also quite surprised at just the scale and the lack of jobs, and salaries, and level of professionalism generally (Phase 2).

The connection between participants' partners' happiness and overall adjustment is also evident in the positive comments from another participant, whose partner is also English:

Oh look, it has been really, really easy. And for < partner $>$ more so, he enjoys going to work now whereas he has not for years. Lifestyle is brilliant, and yeah, overall I think we've both been surprised at how easy it has been to come back, and just kind of get settled in so fast. (Ashley, Phase 2)

Because of the frequency of participants talking about their partners' re-adjustment alongside their own, a query was initiated in NVivo. From this, we concluded that the partnered participants either had very positive or very negative initial repatriation outcomes, 
which appeared highly dependent on the level of the partners' adjustment. When partners adjusted easily and found work, this positively affected participants' assessment of repatriation outcomes. When partners struggled, this had a negative impact.

\section{Research}

Participants researched specific aspects of life back in New Zealand prior to making their decision to repatriate. The first of these was the cost of living, and in particular, groceries. The Internet was the most common method in which research was conducted prior to repatriation. The following comment is typical in phase 1 :

Well we've done some price comparisons. We did a fake online shop with Countdown to compare food prices. (Sarah, phase 1)

The cost and availability of housing was another aspect investigated:

I've already started looking a little bit. And it turns out that just when I was back last time, one of my buddies from university was moving up there [Whangarei], someone else is moving, my roommate from university is moving up, other friends are planning on moving there, so it seems to be a reasonable option. And prices are not insane. (David, phase 1)

Participants were instantly able to access current prices and availability previously only available through newspapers, and hence were much better informed.

\section{Connectivity with home country}

In addition to the proactive research participants conducted into life and work in New Zealand, it emerged that people tended to retain a sense of connection with New Zealand throughout their time living abroad. From a social perspective, people kept connections active through Facebook and other networking sites. They also kept in touch with news in New Zealand, including house prices and costs of living, through news feeds or by visiting New Zealand-based news sites. Unsurprisingly, family was also a key connection that had been retained by Amanda:

My parents have been really good at keeping me in touch with things going on in New Zealand, whether it's little social media things, or bigger issues like elections, budgets and stuff. (Amanda, phase 1)

Participants also tended to visit New Zealand with reasonable frequency, with most visiting New Zealand every 1-2 years. The outcome of this tended to be a sense of remaining informed about life in New Zealand throughout the time abroad.

\section{Discussion}

The objective of this article is to explore the re-adjustment of repatriating SIEs by comparing prior-repatriation expectations and after-repatriation experiences, as well as analysing attributions to the re-adjustment process. Further, we revisit Black et al.'s (1992) framework of repatriation adjustment and suggest alterations to make it more relevant to the repatriation experiences of these SIEs.

We consider our study important in that we go further than Guo et al.'s (2013) focus on motivation to repatriate and the challenges perceived by SIEs prior to their return, and beyond intention to repatriate (e.g. Tharenou and Caulfield, 2010) to examine the actual experience of repatriation. We found that participants had realistic expectations of their return, fuelled by knowledge of both the work and non-work elements of life in New Zealand. This knowledge was, in turn, driven by an unbroken connection with New Zealand during 
expatriation - using digital technology to keep in touch with people and news, relatively frequent visits to New Zealand, and proactive investigations participants conducted when deciding to repatriate. Proactivity has been identified previously as a facilitator for AE readjustment (Lazarova and Cerdin, 2007; O'Sullivan, 2002), and it is logical that this sample of SIEs, who had been motivated to leave their home country to live and work overseas, also showed strong proactivity about their return.

More specifically, we provide qualitative evidence on how SIEs understand and demonstrate proactivity through research and maintaining home connections. Individual agency is strongly shown in the study. This is essentially the process of repatriation adjustment that is missing in the current SIE literature. As identified in the work by Martin (1984), it is the discrepancy between the expectations and the experience which impacts readjustment, resulting in reverse culture shock. Our study shows that the repatriation experience either met or exceeded their expectations, revealing strong congruence, and suggesting that the re-adjustment in the digital age might be easier than anticipated. The notion of reverse culture shock is mitigated by ongoing connections to the home country through Internet research and constant communication with family and friends through phone calls and emails. This finding illustrates the importance of Tung's (2016) call to ensure research reflects the realities of the day.

Importantly, this study suggests that the repatriation experiences can be attributed to both individual agency (e.g. proactive research of work and life in New Zealand) and contextual factors (e.g. the state of the employment market in New Zealand). The implication here is that SIE re-adjustment may not only be home country-specific but also be outside the control of the repatriating individual. Connection with home and information access have key roles to play in re-adjustment and provide a contemporary addition to the re-adjustment literature. The information age, development of and increased use of handheld mobile devices and the rise of social media have not only enabled but actually encouraged people to stay in touch with others across the other side of the world.

These contributions are included in our reconfiguration of the repatriating SIE readjustment framework adapted from Black et al.'s (1992) framework of AE adjustment. Figure 1 shows this new framework, summarising and generalising our main findings. We specify our contributions by colour-coding the different components of the framework. Grey represents original themes that are not supported by the current study; black features the original themes that are supported by our findings; and blue highlights new themes that we add to the conceptual framework. We now elaborate on this renewed conceptualisation of SIE re-adjustment.

First, we examine the greyed areas of the framework. The individual variable of length of time overseas did not feature as a determinant in the re-adjustment of SIEs when an NVivo query was initiated. The literature on $\mathrm{AE}$ adjustment is also inconclusive on this variable, with some research suggesting a negative relationship (Tahir and Azhar, 2013), although other studies show little impact (Suutari and Välimaa, 2002). Tharenou and Caulfield's (2010) study on the repatriation of SIEs finds that years abroad is negatively related to intention to repatriate, but no relationship with actual repatriation is shown. We posit here that the individual agency of the SIE may be over-riding the length of time abroad. The participants in this study had a strong emotional commitment to repatriating, had experienced considerable physical and emotional upheaval and wanted to be successful in New Zealand.

For the in-country adjustment, both the need for control and expatriate adjustment have been subsumed by personal characteristics. This reflects the level of individual agency of the SIE as discussed above, and the existence of certain characteristics (e.g. flexibility and organisation skills) that make re-adjustment easier.

The job variables of task independence in the host country and role clarity, discretion and conflict in the home country are not apparent in the current study and therefore have also 
been excluded from our SIE re-adjustment framework. As the SIE is leaving their employment in the host country, the level of independence is not relevant to the returnee. Further, as the SIE is responsible for finding their own employment in the home country (Begley et al., 2008), the challenge faced by AEs of returning to a role in the home base of the multinational company is not relevant. SIRs enjoy the freedom and independency of job selection. Hence, for these highly skilled participants, they were able to evaluate and select the appropriate job facilitating an easy settlement back in New Zealand.

Relatedly, we have also removed all organisational factors from the framework, both in the host and home countries, as for the repatriating SIE, the organisation is not a controlling factor. Social status and housing conditions were not identified as components impacting readjustment. In the original model, these non-work factors reflected the loss of status from being an expatriate, accustomed to a rich lifestyle (Stroh et al., 1998) and the risk that the standard of housing in the home country may not be comparable to the expatriate accommodation. The repatriating SIE, in order to meet our definition, was an SIE in the host country, and hence does not have the "status" of the expatriate, but is more akin to a local employee. SIEs have not had the benefits of compensatory packages often provided to expatriates (Akkan et al., 2018), so there is no impact on re-adjustment.

Some factors that are proposed in Black et al.'s (1992) repatriation adjustment framework are also highlighted as relevant in this article. Our study re-iterated the finding that visiting home was an important component of re-adjustment. Participants returned often, and the frequent exposure to the ways things were perhaps had the effect of mitigating the rate of change that was occurring in the home country.

We have also retained the concept of cultural distance as a non-work variable, although we have broadened this concept to "contextual factors". The key assumption behind cultural distance is that the greater the distance between the host and home country, the greater the magnitude of adjustment required (Tung, 2017). In this article, many of participants had been based in the United Kingdom, a country with close cultural proximity to New Zealand in many ways, and this may have eased their re-adjustment. However, the United Kingdom is dissimilar in other ways that are not generally incorporated into the understanding of cultural distance. For example, differences in climate, pace of life and financial relativity are all aspects mentioned by participants in this study. These are included in our understanding of contextual factors.

On the in-country adjustment side of the framework, we recognise the importance of partner adjustment as a component of re-adjustment to the home country. In terms of unmet expectations, the role of significant others in the EA literature has been considered critical (Akkan et al., 2018). In the case of repatriating SIEs, our research suggests that this might be even more critical for two reasons. First, the risks and costs of returning to the home country (e.g. the cost of return and employment issues) are greater for SIEs, and if the partner is not adjusting well, this could result in a re-expatriation. Second, many of our participants were returning to New Zealand with a partner from another country, so the partners were actually expatriating, with expectations of their own. If these expectations are not met, this could cause tension. We would expect that foreign partners could be a common occurrence and not something specific to our participants, reinforcing the salience of this factor.

We have also added new themes to Black et al. (1992)'s conceptualisation of re-adjustment. Many of our participants expressed a readiness to return to the home country. Again this highlights the personal agency repatriating SIEs have in their decision to return home and the timing of that event, and emphasises the difference between AEs who usually have a fixed contract or a predetermined time they will be away and their mobility decision is controlled by organisational factors (Chiang et al., 2017). Repatriation preparedness is an important variable impacting readjustment (Andresen and Walther, 2013). The extent to which
Repatriation of SIEs 
participants in this study were equipped, both emotionally and logistically in terms of becoming informed about life and work in New Zealand prior to repatriating, can be seen to demonstrate the importance of preparedness.

Proactivity such as maintaining connectivity and research, as discussed in the findings section, are included as non-work variables. A significant aspect of these factors is that the findings suggest information gathering and re-adjustment processes begin much earlier than repatriation itself, challenging the notion that repatriation is a separate part of expatriation experiences (Andresen et al., 2014). In other words, there would seem to be a psychological adjustment which occurs before the physical relocation. Again, the un-severed connection with New Zealand contributed to this, including continued "touch points" with the home country, frequent conversations with family and other contacts, or reading about New Zealand events online, during participants' time abroad. The maintenance of these connections was enabled and encouraged by modern technologies, including Skype, social media and handheld mobile devices (Baruch et al., 2016; Sabates-Wheeler et al., 2009). Hence, this resulted in "softening the blow" of the actual move.

Finding employment on return to the home country was a key concern for many of the participants. The concerns focused not just on obtaining employment, but the level of employment, the salary and the difficulties of dealing with recruitment agencies. Their concerns were valid - a lack of local career capital has been demonstrated to hinder employment of repatriate SIEs (Guo et al., 2013), and lack of recognition of skills developed internationally by home country employers has meant that SIEs have had to settle for lower level positions back home (Begley et al., 2008). However, finding work was relatively easy for the participants, with only two still looking for work in the second phase of this study. It is likely that these highly skilled workers had, as Valk et al. (2015) suggest, been able to transfer their competencies to the home country.

As a result of our research, lifestyle has also been included in the framework. The overwhelming majority of participants were anticipating and experienced an improvement in their lifestyle as a result of the move home. Expectations of an improved lifestyle had also counterbalanced negative work expectations. Tharenou and Caulfield (2010) include lifestyle in their model, incorporating it as a pull to repatriate and link it to intention to repatriate, but not to re-adjustment within the home country. The evidence here in the New Zealand context suggests that lifestyle is very much part of the re-adjustment process and may in fact act as a buffer to the negative aspects of re-adjustment.

There is one final point to discuss in the framework of SIE adjustment. Black et al. (1992) showed two distinct temporal dimensions in their model implying that repatriates can only align with either the host or the home country culture at any one time. The interviews with participants, however, exposed a strong emotional connection with New Zealand throughout the expatriation, which assisted them in their re-adjustment. Again, ease of access to information in recent years has minimised this separation. While recognising that there is a physical relocation at some point (the move back to New Zealand), we illustrate the temporal dimension here as a continuum of time.

\section{Conclusion}

It is useful to consider this study's contribution to the small, yet emerging, body of literature on SIE repatriation. First, repatriation is an under-researched phase of expatriation, and particularly SIE (Akkan et al., 2018; Chiang et al., 2017), and the empirical data here contributes to our understanding of the construct. Specifically, our research shows a relatively strong level of congruence between participants' expectations and experiences of repatriation, and a relative ease of re-adjustment along with other positive work and non-work-related outcomes not uniformly seen in relation to assigned 
repatriation. Further, this study examines the longitudinal aspect of repatriation, focusing not just on intention to repatriate, but the actual relocation to the home country and the experience of that process. By comparing experiences with expectations, we are able to capture the dynamics of issues faced by returning SIEs. The nature of continuum of time during the repatriation process highlights expatriation/repatriation as a holistic, interrelated process.

Second, we address Tung's (2016) concern that we need research that reflects today's world. This article's findings re-examine Black et al.'s framework of repatriation adjustment in the context of contemporary SIE, identifying the absence of the organisation for the SIE and highlighting the power of connectivity and research in mitigating reverse culture shock and easing re-adjustment. In doing so, the article also challenges other conclusions that repatriates experience much higher levels of personal, cultural and emotional difficulties during return than expatriation (Adler, 1981; Martin, 1984; Szkudlarek and Sumpter, 2015).

The article also offers practical implications at a range of levels. Organisational decisionmakers need to focus on understanding the characteristics of returning SIEs, the drivers behind their move home and their objectives for their careers. While lifestyle was a major factor in the decision to return for many of this study's participants, there was no evidence that any participant intended to rest on their laurels after returning. On the contrary, while participants were prepared to earn less than they did abroad, they did wish to maintain their careers, have their skills and experience from abroad recognised and contribute to organisations in meaningful ways. It is also prudent to recognise that repatriation is not necessarily a permanent move for many participants; should their experiences not live up to expectations, they are prepared to move jobs, and even countries. To this end, leveraging their experience and institutionalising their knowledge before they move on are important steps.

On an individual level, the main implication of this study for repatriating SIEs and those who intend to return is that repatriation is not always a negative experience. It is important that this message reaches people who are considering returning. To improve repatriation experiences, SIEs stay abreast of news and events in the home country and maintain professional connections and networks while abroad. Finally, repatriating SIEs should take the time to conduct proactive research into work and broader life in the home country, before returning.

While these contributions add to the body of knowledge, this research, and more specifically the comparison with Black et al.'s (1992) framework for AE readjustment, provides direction for the future of repatriating SIE research. Our results suggest that readjustment can be eased with mitigating conditions - in our case, quality of life back home had a positive impact on the ease of readjustment. Future studies could explore further to see if there are other mitigating factors which have a similar effect. For example, for SIEs who have been located in culturally very different countries, the relief of returning to family, friends and the natural language might compensate for other challenges. An investigation into the interplay between the various variables impacting re-adjustment may be productive in developing our understanding of repatriation of SIEs.

The role of the partner and family warrants further attention. Lazarova et al. (2010) highlighted the need to incorporate family role adjustment within the AE literature, and our results suggest that this is also important for repatriating SIEs. Specifically, our results suggest that the (re-)adjustment of the partner impacts the readjustment of the SIE. There is scope to compare the effect of the partner being a repatriate and returning to their home country as opposed to the partner being an expatriate and moving to a new country.

A third area for future investigation which is highlighted by our research is the temporal component of readjustment. Black et al.'s (1992) original framework showed two distinct time 
frames, while our results suggest more of a continuum, with repatriation planning happening much earlier than previously thought. Further investigation over the full process of repatriation and for some time after could reveal information about the level of readjustment at varying times of the process.

Finally, we recognise the limitations of our study. The sample used in this study is of relatively homogenous highly skilled SIEs, primarily hosted in the United Kingdom. The impact here is that repatriating SIEs who are not in the highly skilled category may have different experiences. Home-host cultural similarity can reduce otherwise present readjustment difficulties (Tharenou and Caulfield, 2010), and insufficient data from hosts other than the United Kingdom has constrained the ability to draw broader conclusions. However, the high volume of New Zealand expatriates in the United Kingdom (Thorn, 2009), enabled by the relative ease of visas, justifies a focus on this context. Further studies could focus on repatriating SIEs from more diverse occupations (e.g. blue collar workers) and cultural contexts (e.g. China) to see if different expectations/ experiences exist.

We also acknowledge that the adjusted framework proposed here may not cover the breadth of factors that impact SIE's re-adjustment. It was not our intention to propose a fixed model, but rather we aimed to demonstrate the dynamic nature of the factors affecting adjustment for this group of repatriate New Zealanders. Further testing would be required to ensure that these factors were relevant to others and to gather a deeper understanding of the relationships between the factors.

\section{References}

Adler, N. (1981), "Re-entry: managing cross-cultural transitions", Group and Organization Studies, Vol. 6 No. 3, pp. 341-356.

Akkan, E., Lazarova, M. and Reiche, B. (2018), "The role of repatriation in and for global careers", in Dickmann, M., Suutari, V. and Wurtz, O. (Eds), The Management of Global Careers, Palgrave McMillan, Cham, pp. 223-256.

Al Ariss, A. and Crowley-Henry, M. (2012), "Self-initiated expatriation and migration in the management literature: present theorizations and future research directions", Career Development International, Vol. 18 No. 1, pp. 78-96.

Altman, Y. and Baruch, Y. (2012), "Global self-initiated corporate expatriate careers: a new era in international assignments?”, Personnel Review, Vol. 41 No. 2, pp. 233-255.

Andresen, M. and Walther, M. (2013), "Self-initiated repatriation at the interplay between field, capital, and habitus: an analysis based on Bourdieu's theory of practice", in Walther, M., Andresen, M. and Nowak, C. (Eds), Self-initiated Expatriation - Individual, Organisational and National Perspectives, Routledge, New York, NY, pp. 160-180.

Andresen, M., Bergdolt, F., Margenfeld, J. and Dickmann, M. (2014), "Addressing international mobility confusion - developing definitions and differentiations for self-initiated and assigned expatriates as well as migrants", International Journal of Human Resource Management, Vol. 25 No. 16, pp. 2295-2318.

Baruch, Y., Altman, Y. and Tung, R. (2016), "Career mobility in a global era: advances in managing expatriation and repatriation", The Academy of Management Annals, Vol. 10 No. 1, pp. 841-889.

Begley, A., Collings, D. and Scullion, H. (2008), "The cross-cultural adjustment experiences of selfinitiated repatriates to the Republic of Ireland labour market”, Employee Relations, Vol. 30 No. 3, pp. 264-282.

Black, J.S. and Gregersen, H.B. (1991), "Antecedents to cross-cultural adjustment for expatriates in Pacific Rim assignments”, Human Relations, Vol. 44 No. 5, pp. 497-515. 
Black, J.S., Gregersen, H.B. and Mendenhall, M.E. (1992), "Toward a theoretical framework of repatriation adjustment”, Journal of International Business Studies, Vol. 23 No. 4, pp. 737-760.

Brewster, C., Mäkelä, L. and Suutari, V. (2019), "Careers of highly educated self-initiated expatriates: observations from studies among Finnish business professionals", in Global Mobility of Highly Skilled People, Springer, Cham, pp. 41-60.

Brookfield Global Relocation Services (2012), “Global relocation trends: 2012 survey report”, Brookfield Global Relocation Services, Woodridge, IL.

Brookfield Global Relocation Services (2016), "2016 global mobility trends survey”, available at: http:// globalmobilitytrends.bgrs.com/\#/section-4?q=27 (retrieved 17 October 2018).

Cao, L., Hirschi, A. and Deller, J. (2014), "Perceived organizational support and intention to stay in host countries among self-initiated expatriates: the role of career satisfaction and networks", International Journal of Human Resource Management, Vol. 25 No. 14, pp. 2013-2032.

Cao, L., Hirschi, A. and Deller, J. (2013), "The positive effects of a protean career attitude for self-initiated expatriates: cultural adjustment as a mediator", Career Development International, Vol. 18 No. 1, pp. 56-77.

Cappellen, T. and Janssens, M. (2010), "Characteristics of international work: narratives of the global manager", Thunderbird International Business Review, Vol. 52 No. 4, pp. 337-348.

Cerdin, J.-L. and le Pargneux, M. (2009), "Career and international assignment fit: toward an integrative model of success", Human Resource Management, Vol. 48 No. 1, pp. 5-25.

Cerdin, J.-L. and Selmer, J. (2014), "Who is a self-initiated expatriate? Towards conceptual clarity of a common notion", International Journal of Human Resource Management, Vol. 25 No. 9, pp. 1281-1301.

Chiang, F., van Esch, E., Birtch, T. and Shaffer, M. (2017), "Repatriation: what do we know and where do we go from here", International Journal of Human Resource Management, Vol. 29 No. 1, pp. 188-226.

Cho, T., Hutchings, K. and Marchant, T. (2013), "Key factors influencing Korean expatriates' and spouses' perceptions of expatriation and repatriation", International Journal of Human Resource Management, Vol. 24 No. 5, pp. 1051-1075.

Dickmann, M., Suutari, V., Brewster, C., Mäkelä, L., Tanskanen, J. and Tornikoski, C. (2018), "The career competencies of self-initiated and assigned expatriates: assessing the development of career capital over time”, International Journal of Human Resource Management, Vol. 29 No. 16, pp. 2353-2371.

Doherty, N., Dickmann, M. and Mills, T. (2011), "Exploring the motives of company-backed and selfinitiated expatriates", International Journal of Human Resource Management, Vol. 22 No. 3, pp. 595-611.

Doherty, N., Richardson, J. and Thorn, K. (2013), "Self-initiated expatriation and self-initiated expatriates: clarification of the research stream", Career Development International, Vol. 18 No. 1, pp. 97-112.

Fitzpatrick, F. (2017), "Taking the "culture" out of "culture shock" - a critical review of literature on cross-cultural adjustment in international relocation", Critical Perspectives on International Business, Vol. 13 No. 4, pp. 278-296.

Forster, N. (1994), "The forgotten employees? The experiences of expatriate staff returning to the UK", International Journal of Human Resource Management, Vol. 5 No. 2, pp. 405-425.

Froese, F.J. (2012), "Motivation and adjustment of self-initiated expatriates: the case of expatriate academics in South Korea", International Journal of Human Resource Management, Vol. 23 No. 6, pp. 1095-1112.

Goss, Y. and Hynes, G.E. (2005), "Strategies for successful repatriation", Journal of International Business Research, Vol. 4 No. 1, pp. 97-109. 
Guo, C., Porschitz, E.T. and Alves, J. (2013), "Exploring career agency during self-initiated repatriation: a study of Chinese sea turtles", Career Development International, Vol. 18 No. 1, pp. 34-55.

Harris, H. and Brewster, C. (1999), "The coffee-machine system: how international selection really works", International Journal of Human Resource Management, Vol. 10 No. 3, pp. 488-500.

Hasleberger, A. and Vaiman, V. (Eds) (2013), Managing Talent of Self-Initiated Expatriates: A Neglected Source of the Global Talent Flow, Palgrave McMillan, Basingstoke.

Inkson, K., Arthur, M., Pringle, J. and Barry, S. (1997), "Expatriate assignment versus overseas experience: contrasting models of international human resource development", Journal of World Business, Vol. 32 No. 4, pp. 351-368.

Inkson, K., McNulty, Y. and Thorn, K. (2013). "The global careers of Australians and New Zealanders", in Reis, C. and Baruch, Y. (Eds), Careers without Borders, Routledge, New York, NY, pp. 135-160.

Jannesari, M. and Sullivan, S.E. (2019), "Career adaptability and the success of self-initiated expatriates in China", Career Development International, Vol. 24 No. 4, pp. 331-349.

KEA New Zealand (2015), The KEA Every Kiwi Counts Survey [online], available at: http://www. keanewzealand.com/ekc-2013.

Knocke, J. and Schuster, T. (2017), "Repatriation of international assignees: where are we and where do we go from here? A systematic literature review", Journal of Global Mobility: The Home of Expatriate Management Research, Vol. 5 No. 3, pp. 275-303.

Kraimer, M., Bolino, B. and Mead, B. (2016), "Themes in expatriate and repatriate research over four decades: what do we know and what do we still need to learn?", Annual Review of Organizational Psychology and Organizational Behavior, Vol. 3, pp. 83-109.

Lazarova, M. (2014). "Taking stock of repatriation research”, in Collings, D., Wood, G. and Caligiuri, P. (Eds), The Routledge Companion to International Human Resource Management, Routledge, Oxon, pp. 378-398.

Lazarova, M. and Cerdin, J.-L. (2007), "Revisiting repatriation concerns: organizational support versus career and contextual influences", Journal of International Business Studies, Vol. 38 No. 3, pp. 404-429.

Lazarova, M., Westman, M. and Shaffer, M. (2010), "Elucidating the positive side of the work-family interface on international assignments: a model of expatriate work and family performance", Academy of Management Review, Vol. 35 No. 1, pp. 93-117.

Lindsay, V., Sharma, R.R. and Rashad, S. (2017), "How likely am I to return home? A study of New Zealand self-initiated expatriates", Asia Pacific Journal of Human Resources, Vol. 57, pp. 57-84.

Lofland, J., Snow, D., Anderson, L. and Lofland, L. (2006), Analysing Social Settings: A Guide to Qualitative Observation and Analysis, 4th ed., Belmont, Wadsworth.

Martin, J.N. (1984), "The intercultural reentry: conceptualization and directions for future research", International Journal of Intercultural Relations, Vol. 8 No. 2, pp. 115-134.

Martin, J.N. and Harrell, T. (2004). "Intercultural reentry of students and professionals: theory and practice", in Handbook of Intercultural Training, SAGE Publications, Thousand Oaks, CA, pp. 309-336.

Mason, J. (2002), "Qualitative interviewing: asking, listening and interpreting”, in May, T. (Ed.), Qualitative Research in Action, London, Sage.

McNulty, Y. and Brewster, C. (2017), "Theorizing the meaning (s) of 'expatriate': establishing boundary conditions for business expatriates", International Journal of Human Resource Management, Vol. 28 No. 1, pp. 27-61.

Meuer, J., Tröster, C., Angstmann, M., Backes-Gellner, U. and Pull, K. (2019), "Embeddedness and the repatriation intention of assigned and self-initiated expatriates", European Management Journal, Vol. 37 No. 6, pp. 784-793. 
OECD (2014), OECD Economic Outlook, OECD, Paris.

O'Sullivan, S.L. (2002), "The protean approach to managing repatriation transitions", International Journal of Manpower, Vol. 23 No. 7, pp. 597-616.

Pratt, M., Rockmann, K. and Kaufmann, J. (2006), "Constructing professional identity: the role of work and identity learning cycles in the customization of identity among medical residents", Academy of Management Journal, Vol. 49 No. 2, pp. 235-262.

Sabates-Wheeler, R., Taylor, L. and Natali, C. (2009), "Great expectations and reality checks: the role of information in mediating migrants' experience of return", European Journal of Development Research, Vol. 21 No. 5, pp. 752-771.

Selmer, J. and Lauring, J. (2012), "Reasons to expatriate and work outcomes of self-initiated expatriates", Personnel Review, Vol. 41 No. 5, pp. 665-684.

Shaffer, M. and Harrison, D. (1998), "Expatriates' psychological withdrawal from international assignments: work, nonwork, and family influences", Personnel Psychology, Vol. 51 No. 1, pp. 87-118.

Stroh, L., Gregersen, H. and Black, J. (1998), "Closing the gap: expectations versus reality among repatriates", Journal of World Business, Vol. 33 No. 2, pp. 111-124.

Sussman, N.M. (2002), "Testing the cultural identity model of the cultural transition cycle: sojourners return home", International Journal of Intercultural Relations, Vol. 26 No. 4, pp. 391-408.

Suutari, V. and Brewster, C. (2000), "Making their own way: international experience through selfinitiated foreign assignments", Journal of World Business, Vol. 35 No. 4, pp. 417-436.

Suutari, V. and Välimaa, K. (2002), "Antecedents of repatriation adjustment: new evidence from Finnish repatriates", International Journal of Manpower, Vol. 23 No. 7, pp. 617-634.

Suutari, V., Brewster, C. and Dickmann, M. (2018). "Contrasting assigned expatriates and self-initiated expatriates: a review of extant research and a future research agenda", in Dickmann, M., Suutari, V. and Wurtz, O. (Eds), The Management of Global Careers: Exploring the Rise of International Careers, Springer, London, pp. 63-89.

Szkudlarek, B. (2010), "Reentry-A review of the literature", International Journal of Intercultural Relations, Vol. 34 No. 1, pp. 1-21.

Szkudlarek, B. and Sumpter, D. (2015), "What, when, and with whom? Investigating expatriate reentry training with a proximal approach", Human Resource Management, Vol. 54 No. 6, pp. 1037-1057.

Tahir, R. and Azhar, N. (2013), "The adjustment process of female repatriate managers in Australian and New Zealand (ANZ) companies", Global Business Review, Vol. 14 No. 1, pp. 155-167.

Tharenou, P. and Caulfield, N. (2010), "Will I stay or will I go? Explaining repatriation by self-initiated expatriates", Academy of Management Journal, Vol. 53 No. 5, pp. 1009-1028.

Thomas, D. (2006), "A general inductive approach for analyzing qualitative evaluation data", American Journal of Evaluation, Vol. 27 No. 2, pp. 237-246.

Thorn, K. (2009), “The relative importance of motives for international self-initiated mobility”, Career Development International, Vol. 14 No. 5, pp. 441-464.

Tung, R. (2016), "New perspectives on human resource management in a global context", Journal of World Business, Vol. 51 No. 1, pp. 142-152.

Tung, R. (2017), "Prologue: voyages of self-discovery: a reflection on four decades of research on expatriation and cross-cultural Interactions", in Verbeke, A., Puck, J. and van Tulder, R. (Eds), Distance in International Business: Concept, Cost and Value, pp. 1-15.

Valk, R., van der Velde, M., van Engen, M. and Szkudlarek, B. (2015), "Warm welcome or rude awakening? Repatriation experiences of Indian and Dutch international assignees and intention to leave the organisation", Journal of Indian Business Research, Vol. 7 No. 3, pp. 243-270. 
Vidal, M.E.S., Valle, R.S. and Aragón, M.I.B. (2010), "Analysis of the repatriation adjustment process in the Spanish context”, International Journal of Manpower, Vol. 31 No. 1, pp. 21-41.

\section{Corresponding author}

Kaye Thorn can be contacted at: k.j.thorn@massey.ac.nz

For instructions on how to order reprints of this article, please visit our website: www.emeraldgrouppublishing.com/licensing/reprints.htm Or contact us for further details: permissions@emeraldinsight.com 